\title{
Analysis and Comparison of Correlation between Camper's Plane and Natural Occlusal Plane in Normal Dentulous Subjects
}

\author{
${ }^{1}$ Nirav Rathod, ${ }^{2}$ Prachi Sood, ${ }^{3}$ Nirmala Pasam
}

\begin{abstract}
Background: Orientation of the occlusal plane is one of the most important clinical procedures in the prosthodontic rehabilitation of edentulous patients but definitions of the ala-tragus line (ATL) causes confusion, because the exact points of reference for this line are not clear.

Aim: The aim of this study was to corroborate a correlation between Camper's plane and natural occlusal plane in normal dentulous subjects and to ascertain the most relevant posterior reference point for establishing Camper's plane.

Materials and methods: In this study, 40 subjects with complete natural dentition and Angel's Class I occlusal relationship were selected. The subjects were photographed in sitting erect posture with head unsupported while clenching on a fox plane. The angles between the following lines were measured using digital screen protractor, the occlusal plane and Ala to superior border of tragus, the occlusal plane and Ala to middle border of tragus, as well as occlusal plane and Ala to inferior border of tragus. Descriptive statistics, one sample t-test and, independent t-test were done to analyze the data.
\end{abstract}

Results: There was no parallelism between the occlusal plane and ATL with three different posterior ends and one sample t-test showed that the angles between them were significantly different from zero $(p<0.001)$. However, the inferior border of the ATL had the lowest mean angle, $1.99^{\circ}$ (4.32) and was almost parallel to the occlusal plane.

Conclusion: Ala-tragus line from Ala of the nose to the inferior border of tragus as a posterior reference point can be considered as a reliable occlusal plane for complete denture fabrication.

Keywords: Ala-tragus line, Camper's plane, Complete denture, Occlusal plane.

How to cite this article: Rathod N, Sood P, Pasam N. Analysis and Comparison of Correlation between Camper's Plane and Natural Occlusal Plane in Normal Dentulous Subjects. Int J Prosthodont Restor Dent 2017;7(3):81-85.

${ }^{1}$ Assistant Professor, ${ }^{2}$ Senior Lecturer, ${ }^{3}$ Reader

${ }^{1}$ Department of Dentistry, Chandulal Chandrakar Memorial Medical College, Bhilai, Chhattisgarh, India

${ }^{2}$ Department of Prosthodontics, Rungta College of Dental Sciences and Research, Bhilai, Chhattisgarh, India

${ }^{3}$ Department of Prosthodontics, Anil Neerukonda Institute of Dental Sciences, Visakhapatnam, Andhra Pradesh, India

Corresponding Author: Nirav Rathod, Assistant Professor Department of Dentistry, Chandulal Chandrakar Memorial Medical College, Bhilai, Chhattisgarh, India, Phone: +919685220600 e-mail: nirav24rathod@gmail.com
Source of support: Nil

Conflict of interest: None

\section{INTRODUCTION}

The orientation of the occlusal plane is one of the most important clinical procedures in the prosthodontic rehabilitation of edentulous patients and because of its effect on esthetics, function, and denture stability, it should be reconstructed as identical as possible to the occlusal plane of missing natural teeth. ${ }^{1,2}$ Occlusal plane is the average plane established by the incisal and occlusal surfaces of the teeth. Generally, it is not a plane but represents the planar mean of the curvature of these surfaces.

Many techniques of establishing the occlusal plane have been reported in the literature but no single method has been shown to be accurate for reliably determining it. Studies that have compared natural and prosthetic occlusal plane are also numerous. ${ }^{3-5}$ Other studies have analyzed and discussed a wide variety of landmarks to show whether they are suitable to use as a reference for occlusal plane orientation. ${ }^{6-12}$ Lips, commissures of mouth, residual ridges, retromolar pad, hamular notchincisive papilla plane, lateral borders of the tongue, and the buccinator grooves are most commonly used intraoral landmarks. ${ }^{6,711-15}$ While many authors ${ }^{16}$ suggest considering intraoral structures during occlusal plane determination, Spratley ${ }^{17}$ believes that the intraoral landmarks are valuable guides for the experienced clinicians but they are rather difficult to follow by students.

Extraoral landmarks that have been suggested to orient the occlusal plane are the interpupillary line, Camper's line, or ATL. ${ }^{10}$ Although the technique for using the Camper's line or ATL is well documented, there is some controversy over whether to take the superior border, the tip, or the inferior border of the tragus of the ear as posterior reference points to define ATL.

The aim of this study is to establish a correlation between Camper's plane and natural occlusal plane in normal dentulous subjects. The objectives of this study are to compare the relationship between Camper's plane and natural occlusal plane in patients within two age groups and to evaluate the most relevant posterior reference point for establishing Camper's plane. 


\section{MATERIALS AND METHODS}

In this study, 40 subjects were included; selection of subjects was done under two age groups: group I: 18 to 25 years and group II: 35 to 45 years and each group consisted of 20 subjects. Patients with fully erupted permanent dentition in Angle's class I molar relationship and with normal overjet and overbite were included in this study. Patients with a history of orthodontic treatment, craniofacial surgery/trauma or patients with temporomandibular joint disorders, marked facial asymmetries, gross occlusal or incisal wear, congenital facial defects or any irregular pattern of occlusion like crossbite were not included in this study. Ethical approval for this study was obtained from the Research Ethics Committee of the Rungta College of Dental Sciences (Ayush University). All appropriate informed consent forms were obtained from all the subjects.

Following case selection, the subjects were seated on chairs with vertical back rest in a relaxed state facing on one side and head oriented in natural horizontal position looking comfortably in a mirror placed 5 feet away from the chair, a fox plane covered with addition silicon putty was given to subjects to hold and bite upon passively (Fig. 1). Ink dots were marked on the inferior border of ala of nose and superior, middle, and inferior points of tragus of ear (Fig. 2).

Left lateral profile photographs were taken with a digital single-lens reflex camera (Canon EOS 600D, 18 megapixels, and $50 \mathrm{~mm}$ Fixed Macro Lens, Tokyo, Japan) mounted on an adjustable tripod (Simpex, VCT691RM) kept at a distance of 5 feet fixed on lateral side of the chair.

All the lateral profile pictures were transferred to the computer system (Dell Inspiron N5050, Penang, Malaysia), to carry out the measurements. Two investigators independently measured the angles between

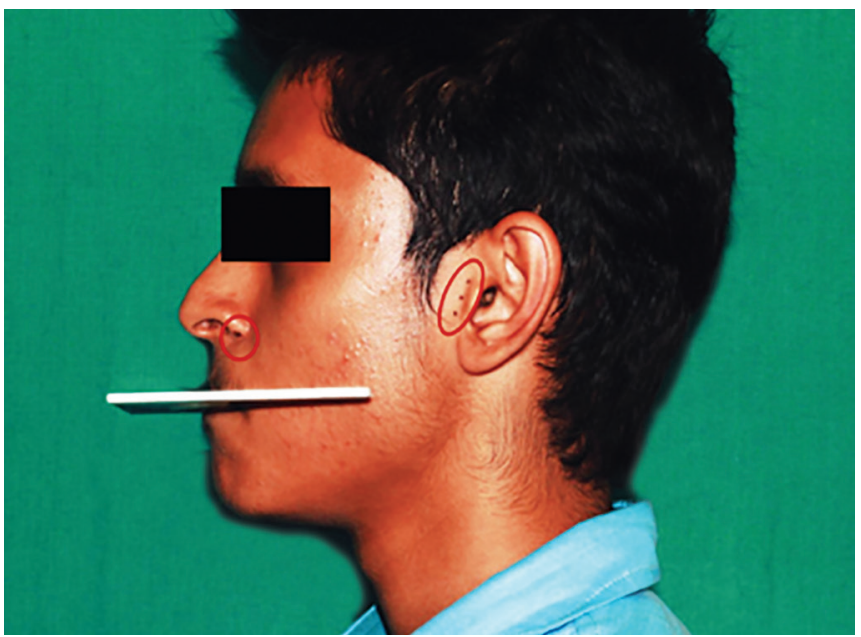

Fig. 1: Subject in natural head position with a Fox plane and three posterior reference points marked the following lines with the help of Screen Protractor Version 4.0 (Iconico, New York, USA).

- Occlusal plane (Fox plane) and the superior border of ala-tragus (OP-ATs).

- Occlusal plane (Fox plane) and the middle of alatragus (OP-ATm).

- Occlusal plane (Fox plane) and the inferior border of ala-tragus (OP-ATi).

Statistical analysis was carried out using Statistical Package for the Social Sciences version 16 (IBM Corp., New York, USA), descriptive statistics, one sample t-test and independent t-test. Test value was zero in one sample t-test, because it was supposed that the occlusal plane and the ATL should be parallel.

\section{RESULTS}

Tables 1 and 2 list the relationship between the occlusal plane and ATL in groups I and II respectively, for all 20 subjects. Statistical analysis, mean values, and standard deviations of the angles between the occlusal plane and the ala-tragus with three posterior point locations are presented in Table 3. One sample t-test showed that the angles between the occlusal plane and ATs, ATm, ATi, are significantly different from zero $(p<0.001)$. The mean angle formed by occlusal plane and ATs is $\left(7.856^{\circ} \pm 4.55\right)$, the mean angle formed by occlusal plane and ATm is $\left(4.69^{\circ} \pm 4.47\right)$ and the mean angle formed by occlusal plane and ATi is $\left(1.99^{\circ}\right.$ \pm 4.32 ). It means that there is no parallelism between the occlusal plane and the ATL with three posterior point locations.

The result showed that the ATi is more closely related to occlusal plane with lowest mean angle $1.99^{\circ}$ (4.32). Pie diagram (Graphs 1 and 2) shows that inferior reference point in tragus is the most relevant point in both groups I and II.

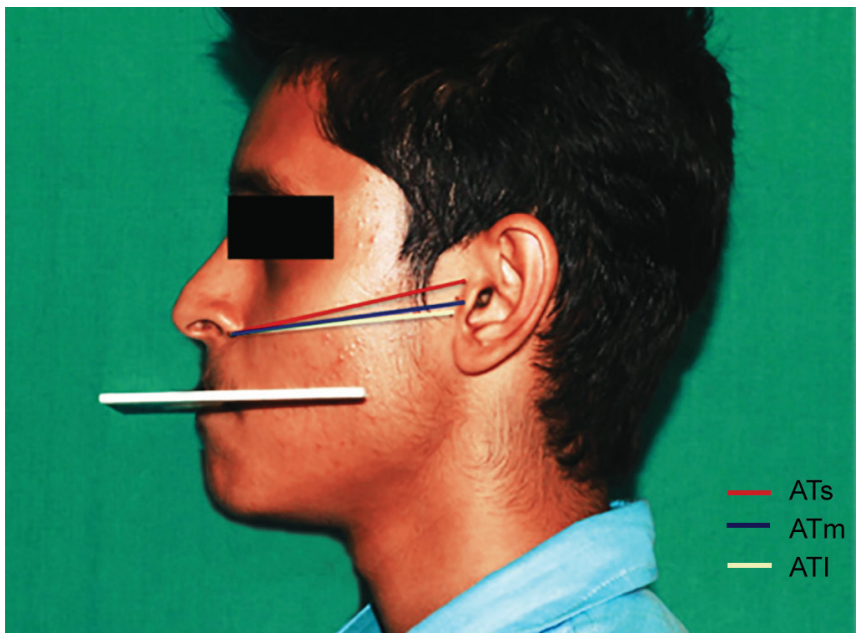

Fig. 2: All three reference lines-ATs, ATm, ATi—were drawn 
Analysis and Comparison of Correlation between Camper's Plane and Natural Occlusal Plane

Table 1: Relationship between natural occlusal plane and ATL in group I (age group 18-25 years)

\begin{tabular}{|c|c|c|c|c|}
\hline \multirow[b]{2}{*}{ Age } & \multicolumn{3}{|c|}{ Angle of measurement } & \multirow[b]{2}{*}{$\begin{array}{l}\text { Most } \\
\text { relevant } \\
\text { posterior } \\
\text { reference } \\
\text { point }\end{array}$} \\
\hline & $\begin{array}{l}\text { Ala to } \\
\text { superior point } \\
\text { of tragus (in } \\
\text { degrees) }\end{array}$ & $\begin{array}{l}\text { Ala to } \\
\text { middle point } \\
\text { of tragus (in } \\
\text { degrees) }\end{array}$ & $\begin{array}{l}\text { Ala to } \\
\text { inferior point } \\
\text { of tragus (in } \\
\text { degrees) }\end{array}$ & \\
\hline 23 & 4.9 & 1.75 & 0.94 & Inferior \\
\hline 21 & 2.14 & 0.92 & -2.67 & Middle \\
\hline 23 & 8.19 & 5.65 & 2.56 & Inferior \\
\hline 24 & 3.58 & 0.01 & -2.99 & Middle \\
\hline 21 & -0.50 & -2.3 & -5.37 & Superior \\
\hline 20 & 7.74 & 5.37 & 3.10 & Inferior \\
\hline 21 & 12.11 & 10.28 & 7.09 & Inferior \\
\hline 19 & 14.55 & 8.45 & 5.40 & Inferior \\
\hline 19 & 13.59 & 10.69 & 9.15 & Inferior \\
\hline 19 & 6.18 & 1.9 & 0.12 & Inferior \\
\hline 19 & 10.99 & 7.59 & 4.9 & Inferior \\
\hline 19 & 7.06 & 3.21 & 0.43 & Inferior \\
\hline 19 & 11.69 & 8.48 & 6.21 & Inferior \\
\hline 20 & 9.9 & 7.27 & 5.62 & Inferior \\
\hline 24 & 4.44 & 0.4 & -1.4 & Middle \\
\hline 20 & 1.69 & 0.48 & -1.86 & Middle \\
\hline 20 & 9.27 & 5.72 & 4.07 & Inferior \\
\hline 19 & 3.17 & 0.16 & -1.22 & Middle \\
\hline 20 & 4.29 & 1.79 & 0.66 & Inferior \\
\hline 19 & 4.93 & 1.57 & -1.26 & Middle \\
\hline
\end{tabular}

Table 2: Relationship between natural occlusal plane and ATL in group II (age group 35-45 years)

\begin{tabular}{|c|c|c|c|c|}
\hline \multirow[b]{2}{*}{ Age } & \multicolumn{3}{|c|}{ Angle of measurement } & \multirow[b]{2}{*}{$\begin{array}{l}\text { Most } \\
\text { relevant } \\
\text { posterior } \\
\text { reference } \\
\text { point }\end{array}$} \\
\hline & $\begin{array}{l}\text { Ala to superior } \\
\text { point of tragus } \\
\text { (in degrees) }\end{array}$ & $\begin{array}{l}\text { Ala to } \\
\text { middle point } \\
\text { of tragus (in } \\
\text { degrees) }\end{array}$ & $\begin{array}{l}\text { Ala to } \\
\text { inferior point } \\
\text { of tragus (in } \\
\text { degrees) }\end{array}$ & \\
\hline 35 & 3.31 & 0.84 & -1.19 & Middle \\
\hline 36 & 4.52 & 1.54 & -1.04 & Middle \\
\hline 39 & 4.97 & 2.37 & -0.84 & Middle \\
\hline 37 & 5.95 & 1.12 & -2.35 & Middle \\
\hline 41 & 13.61 & 10.58 & 6.56 & Inferior \\
\hline 36 & 5.23 & 1.46 & -1.18 & Middle \\
\hline 37 & 8.47 & 3.77 & 0.7 & Inferior \\
\hline 43 & 8.4 & 5.61 & 2.47 & Inferior \\
\hline 39 & 4.87 & 2.34 & 1.06 & Inferior \\
\hline 38 & 15.29 & 12.94 & 9.63 & Inferior \\
\hline 37 & 6.78 & 4.27 & 1.51 & Inferior \\
\hline 40 & 13.95 & 9.82 & 7.04 & Inferior \\
\hline 45 & 8.55 & 5.47 & 1.65 & Inferior \\
\hline 38 & 5.84 & 2.37 & 0.7 & Inferior \\
\hline 41 & 8.79 & 5.52 & 1.25 & Inferior \\
\hline 39 & 10.48 & 7.03 & 3.35 & Inferior \\
\hline 37 & 17.7 & 15.04 & 11.23 & Inferior \\
\hline 35 & 0.43 & -4.38 & -8.04 & Superior \\
\hline 44 & 18.04 & 14.49 & 11.24 & Inferior \\
\hline 38 & 9.17 & 6.03 & 2.48 & Inferior \\
\hline
\end{tabular}

Table 3: Means, SD and significant difference of angles between occlusal plane and ATL with three posterior point locations

\begin{tabular}{|c|c|c|c|c|c|c|c|c|}
\hline \multirow[b]{2}{*}{ Angles } & \multicolumn{3}{|c|}{$A T L(n=40)$} & \multicolumn{2}{|c|}{ Age $18-25(n=20)$} & \multicolumn{2}{|c|}{ Age $35-45(n=20)$} & \multirow[b]{2}{*}{$p$-value $e^{\#}$} \\
\hline & Mean & $S D$ & $p$-value* & Mean & $S D$ & Mean & $S D$ & \\
\hline OP-ATs & 7.856 & 4.55 & $<0.001$ & 6.99 & 4.21 & 8.71 & 4.82 & 0.237 \\
\hline OP-ATm & 4.69 & 4.47 & $<0.001$ & 3.96 & 3.84 & 5.41 & 5.01 & 0.314 \\
\hline OP-ATi & 1.99 & 4.32 & $<0.001$ & 1.67 & 3.89 & 2.31 & 4.8 & 0.647 \\
\hline
\end{tabular}

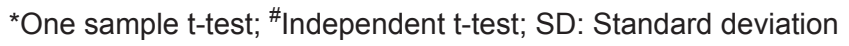

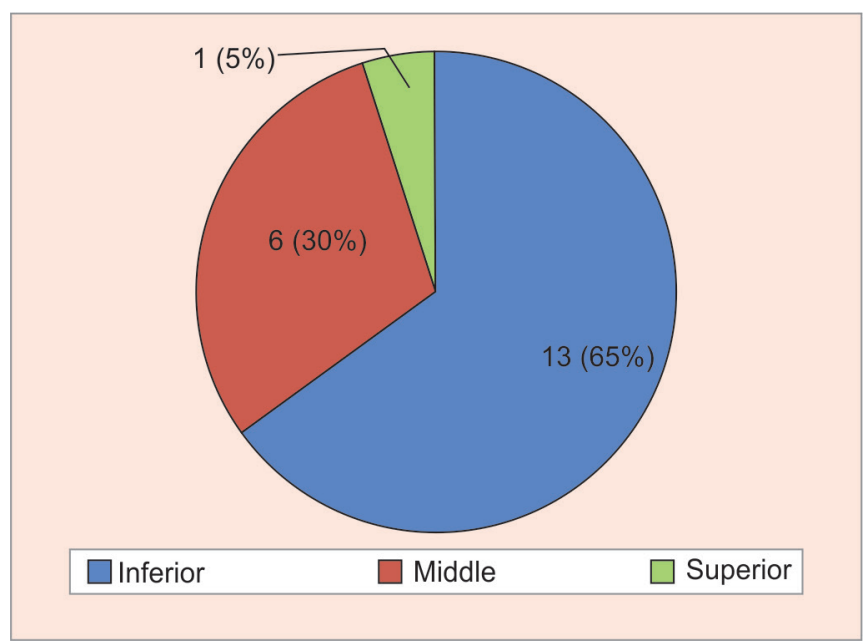

Graph 1: Pie diagram showing population distribution with three posterior reference points in group I

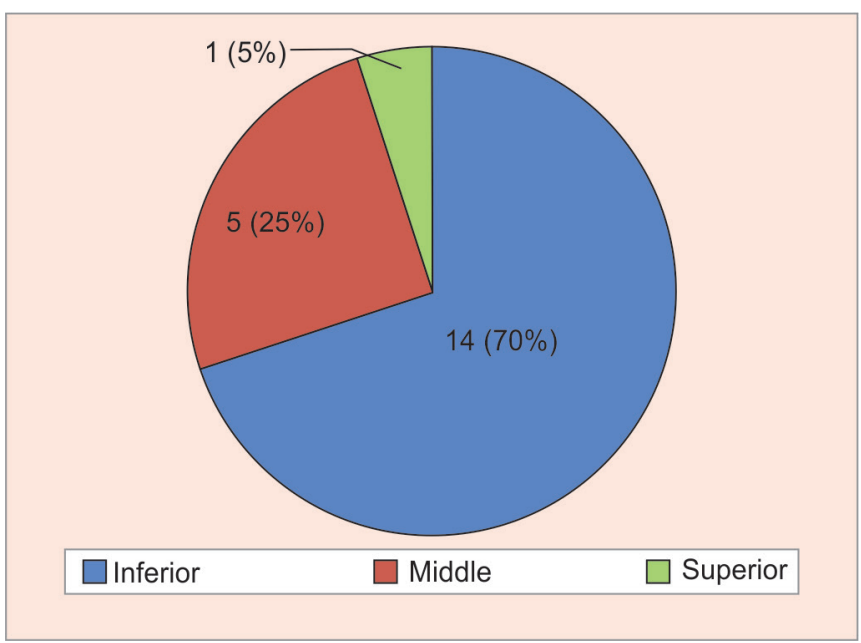

Graph 2: Pie diagram showing population distribution with three posterior reference points in group II 


\section{DISCUSSION}

The occlusal plane is an imaginary surface that is related anatomically to the cranium and theoretically touches the incisal edge of the incisors and tip of cusps of the posterior teeth. It is accomplished with the use of maxillary occlusal rim. The plane must be close to the middle fibers of the buccinator and correctly related to the tongue for proper speech and food bolus control.

The occlusal plane is also an important factor of stability of denture. The best stability is obtained when the occlusal plane is parallel to and anatomically oriented to the ridges. Improper occlusal plane/tipped occlusal plane will lead to shunting effect and loss of stability. If the occlusal plane is lower in the molar area, there will be a tendency for the upper denture to be displaced posteriorly and lower anteriorly. Shunting effect will be opposite if the occlusal plane is lower in incisor area.

Using ATL for establishing occlusal plane is a common method for the fabrication of complete dentures. However, there is some controversy on the posterior reference point of the ATL. The Glossary of Prosthodontics Terms states that the ATL runs from the inferior border of the ala of the nose to some defined point on the tragus of the ear, usually considered to the tip of the tragus. It does not stipulate which part of the tragus should be used as the posterior landmark.

Various authors have given their own definition for ATL. According to Spratley, ${ }^{17}$ it is a line joining the center of ala to the center of tragus. Van Niekerk et $\mathrm{al}^{18}$ concluded from their study that ATL determined using inferior point of tragus could be used as a landmark for orienting the maxillary occlusal plane. Boucher defines ATL as an imaginary line that runs from the inferior border of nose to the superior border of the tragus of the ear. ${ }^{14}$ According to Ismail and Bowman, ${ }^{2}$ it is a line passing from Ala of nose to the center of the tragus.

Due to this dilemma, it was decided to deduce which reference point: the superior, middle, or inferior on the tragus is parallel to the occlusal plane and could be used reliably in clinical practice. The results of this study showed that there is no parallelism between the occlusal plane and the ATL with three different posterior ends. However, the inferior point showed the closest parallelism. The average angle between the occlusal plane and the ala-superior border of tragus in group I is 6.9955 and in group II is 8.7175; the average angle between the occlusal plane and the middle of ala-tragus tragus in group $I$ is 3.9695 and in group II is 5.4115; and the average angle between the occlusal plane and the inferior border of ala-tragus in group I is 1.6740 and in group II is 2.3115 . The inferior border of the ATL had the lowest mean angle (in group I is 1.6740 and in group II 2.3115) and is almost parallel to the occlusal plane.

A study carried out by Karkazis et $\mathrm{al}^{10}$ also advocates the use of the inferior border of tragus as a posterior landmark. Their cephalometric study concluded that the ATL or the Camper's line extending from the lower margin of the ala to the inferior border of the external auditory meatus presented the closest relationship to the natural occlusal plane.

A cephalometric study conducted by Nandeeshwar et $\mathrm{al}^{19}$ concluded that ATL with inferior border of tragus as a posterior reference point can be utilized as a standard occlusal plane in completely edentulous patients.

Rostamkhani et $\mathrm{ll}^{20}$ conducted a cephalometric study in patients with Angle's class III malocclusion and also concluded that the inferior border of the tragus is suggested as the posterior point for ATL orientation.

However, the findings of Solomon ${ }^{21}$ and Sadr and $\mathrm{Sadr}^{22}$ are not in agreement with the above conclusions. In their study, they also concluded that no parallelism exists between occlusal plane and ala-tragus plane, but the ATL (Camper's plane) was found to be closely parallel to the plane of occlusion when the tragal reference point was situated between the superior border and middle of the tragus.

The present study has some limitations which are as follows:

- The study was conducted only in a small population, considering only one geographical location (Chhattisgarh state) and hence the results may vary with morphological changes (in facial/skeletal features) among geographically distributed people.

- The variations due to gender differences in occlusal plane were not considered in the present study.

- The difference in parallelism of the occlusal plane to the ATLs in various malocclusions (Angles class I, II, III) was not studied, which may vary.

\section{CLINICAL SIGNIFICANCE}

This study will be beneficial for both students and practitioners to clarify the confusion in marking the posterior reference point while establishing the ATL during jaw relation procedures for complete denture patients.

\section{CONCLUSION}

Within the limits of the study, it can be said that ATL drawn with inferior border of tragus as posterior reference point is more frequently parallel to standard occlusal plane among the study subjects. The ATL with inferior border of tragus as a posterior reference point can be utilized as a standard occlusal plane in completely edentulous patients. 


\section{REFERENCES}

1. Petricevic N, Celebic A, Celic R, Baucic-Bozic M. Natural head position and inclination of craniofacial planes. Int J Prosthodont 2006 May-Jun;19(3):279-280.

2. Ismail YH, Bowman JF. Position of the occlusal plane in natural and artificial teeth. J Prosthet Dent 1968 Nov;20(5):407-411.

3. Monteith BD. A cephalometric method to determine the angulation of the occlusal plane in edentulous patients. J Prosthet Dent 1985 Jul;54(1):81-87.

4. L'Estrange PR, Vig PS. A comparative study of the occlusal plane in dentulous and edentulous subjects. J Prosthet Dent 1975 May;33(5):495-503.

5. D'Souza NL, Bhargava K. A cephalometric study comparing the occlusal plane in dentulous and edentulous subjects in relation to the maxillomandibular space. J Prosthet Dent 1996 Feb;75(2):177-182.

6. Merkeley HJ. The labial and buccal accessory muscles of mastication. J Prosthet Dent 1954 May;4(3):327-334.

7. Nagle, RJ.; Sears, YH. Denture prosthetics. 2nd ed. St Louis (MO): Mosby; 1962. p. 125-49.

8. Lundquist DO, Luther WW. Occlusal plane determination. J Prosthet Dent 1970 May;23(5):489-498.

9. Abrahams R, Carey PD. The use of the ala-tragus line for occlusal plane determination in complete dentures. J Dent 1979 Dec;7(4):339-341.

10. Karkazis HC, Polyzois GL, Zissis AJ. Relationship between ala-tragus line and natural occlusal plane. Implications in denture prosthodontics. Quintessence Int 1986;17(4):253-255.

11. Celebi A, Valenti-Peruzovi M, Kraljevi K, Brki H. A study of the occlusal plane orientation by intraoral method (retromolar pad). J Oral Rehab 1995 Mar;22(3):233-236.

12. Jayachandran $S$, Ramachandran CR, Varghese R. Occlusal plane orientation: a statistical and clinical analysis in different clinical situations. J Prosthodont 2008 Oct;17(7):572-575.
13. Yasaki M. The height of the occlusion rim and the interocclusal distance. J Prosthet Dent 1961 Jan-Feb;11(1):26-31.

14. Hickey, JC.; Zarb, GA.; Bolender, CL. Boucher's prosthontic treatment for edentulous patients. 9th ed. St Louis (MO): Mosby; 1985. p. 299-300.

15. Fu PS, Hung CC, Hong JM, Wang JC. Three-dimensional analysis of the occlusal plane related to the hamular-incisive papilla occlusal plane in young adults. J Oral Rehabil 2007 Feb;34(2):136-140.

16. Nissan J, Barnea E, Zeltzer C, Cardash HS. Relationship between occlusal plane determinants and craniofacial structures. J Oral Rehabil 2003 Jun;30(6):587-591.

17. Spratley $\mathrm{MH}$. A simplified technique for determining the occlusal plane in full denture construction. J Oral Rehabil 1980 Jan;7(1):31-33.

18. van Niekerk FW, Miller VJ, Bibby RE. The ala-tragus line is complete denture prosthodontics. J Prosthet Dent 1985 Jan;53(1):67-69.

19. Nandeeshwar DB, Ashwin Kumar S, Acharya S. Cephalometric study to determine the relation of ala-tragus line with different posterior reference points from a standard occlusal plane in completely edentulous patients. Asian J Med Clin Sci 2012 Dec;1(3):111-116.

20. Rostamkhani F, Sahafian A, Kermani H. A cephalometric study on the relationship between the Occlusal Plane, Ala-Tragus and Camper's Lines, in patients with Angle's class III malocclusion. J Prosthet Dent 2005 May;2(2):46-49.

21. Solomon EGR. The Morphology of Tragus Part 1: The Confusion about Tragus Terminology. J Indian Prosthodont Soc 2000;11(1):11-15.

22. Sadr K, Sadr M. A study of parallelism of the occlusal plane and ala-tragus line. J Dent Res Dent Clin Dent Prospect 2009 Dec;3(4):107-109. 